\title{
Detection of Rabbit Hemorrhagic Disease Virus GI.2/RHDV2/B in the Mediterranean Pine Vole (Microtus duodecimcostatus) and White- Toothed Shrew (Crocidura russula)
}

\begin{abstract}
Carlos Calvete, ${ }^{1,5}$ Manuel Mendoza, ${ }^{1}$ María P. Sarto, ${ }^{1}$ María P. Jiménez de Bagüés, ${ }^{1}$ Lluis Luján, ${ }^{2}$ Jéssica Molín, ${ }^{2}$ Antonio J. Calvo, ${ }^{3}$ Fernando Monroy, ${ }^{3}$ and Jorge H. Calvo ${ }^{1,4}{ }^{1}$ Animal Production and Health Department, Agrifood Research and Technology Centre of Aragon (CITA), Agrifood Institute of Aragon-IA2 (CITAZaragoza University), Avda, Montañana 930, 50059 Zaragoza, Spain; ${ }^{2}$ Animal Pathology Department, University of Zaragoza, Agrifood Institute of Aragon-IA2 (CITA-Zaragoza University), 50013 Zaragoza, Spain; ${ }^{3}$ Animal Health Management, TRAGSATEC, C/Julián Camarillo 6 A, 28037 Madrid, Spain; ${ }^{4}$ Aragonese Foundation for Research \& Development (ARAID), 50018 Zaragoza, Spain; ${ }^{5}$ Corresponding author (email: ccalvete @ aragon.es)
\end{abstract}

ABSTRACT: The European wild rabbit (Oryctolagus cuniculus) is a key prey species on the Iberian Peninsula, and several predator species that are at risk of extinction are dependent on them as prey. A new rabbit hemorrhagic disease (RHD) virus genotype (GI.2/RHDV2/b) emerged in 2010 and posed a threat to wild rabbit populations. During a survey aimed at investigating RHD epidemiology in wild rabbits, GI.2/RHDV2/b was detected by duplex real-time PCR in carcasses of one Mediterranean pine vole (Microtus duodecimcostatus) and two white-toothed shrews (Crocidura russula). Laboratory New Zealand white rabbits that were challenged with inocula obtained from the liver of the small mammals died showing RHD lesions, confirming the infectiousness of the isolates. Phylogenetic analysis of the VP60 gene nucleotide sequences showed complete homology between the isolates from the two small mammal species and a high degree of similarity, but not complete homology, to GI.2/RHDV2/b sequences from wild rabbits. The GI.2/RHDV2/b genotype has not been reported in species outside the order Lagomorpha.

Key words: Crocidura russula, GI.2/RHDV2/ b, lagovirus, Microtus duodecimcostatus, Oryctolagus cuniculus, rabbit hemorrhagic disease, small mammals.

Rabbit hemorrhagic disease (RHD) is a fatal, highly infectious disease that affects European rabbits (Oryctolagus cuniculus). According to nomenclature proposed by Le Pendu et al. (2017), RHD is caused by the calicivirus species Lagovirus europaeus (GI.1 genotype). In 2010, a new RHD virus genotype, GI.2/RHDV2/b, was identified. Since then, it has spread throughout Western European and is able to infect several species of hares, suggesting a wider spectrum of hosts than other RHD viruses (Le Pendu et al.
2017). We detected GI.2/RHDV2/b in the livers of two species of small wild mammals, identifying infections by this virus in species outside the order Lagomorpha.

We obtained samples during a project to study the epidemiology of RHD in an experimental European rabbit population in four 1 ha enclosures (P1-P4). The experimental population was located on property owned by the Agrifood Research and Technology Centre (CITA) in Zaragoza Province, Spain $\left(41^{\circ} 51^{\prime} 55^{\prime \prime} \mathrm{N}, 0^{\circ} 39^{\prime} 24^{\prime \prime} \mathrm{W}\right)$, where natural wild rabbit populations were absent. The enclosures, which were $2 \mathrm{~km}$ apart, were enclosed by 2.5-m-high wire mesh to prevent the passage of rabbits and their kits, as well as terrestrial predators, but did not prevent access by small mammals or birds. Rabbits lived in natural warrens inside the enclosures. From 2013 to 2016, the population was monitored at least twice per week to collect rabbits that had died from RHD, and from 2014 to 2016, the carcasses of sympatric small mammals were also collected. In all, 37 rabbits that had died from acute RHD were found, and four small mammal carcasses were collected: two Mediterranean pine voles (Microtus duodecimcostatus) were found in September 2014 (Md-Sep14-P3) and November 2014 (Md-Nov14-P3), both in enclosure P3, and two white-toothed shrews (Crocidura russula) were detected in February 2015 in P1 (Cr-Feb15-P1) and in June 2015 in P4 (CrJun15-P4).

Both of the pine voles were adults. Carcass Md-Sep14-P3 was found partially consumed, without a digestive tract or kidneys (sex 
undetermined), whereas Md-Nov14-P3 was a female in a state of advanced pregnancy. One white-toothed shrew, Cr-Feb15-P1, was an adult male, while the other (Cr-Jun15-P4) was a young individual of undetermined sex. At necropsy, no sign of injury or damage caused by predators, scavengers, or insects was evident in any of the last three carcasses. An intense, generalized congestion of the main organs was apparent in the pregnant pine vole specimen (Md-Nov14-P3); however, no sign of any disease was detected in the remaining three carcasses.

Liver samples from the 37 rabbits and the four small mammals were analyzed using duplex real-time PCR (qPCR) to detect RNA from GI.1b/RHDV and GI.2/RHDV2/b lagoviruses in a single analysis (Calvete et al. 2018). Each sample was amplified in duplicate in the same run, and the quantification cycle (Cq) value was calculated as an average of both amplifications. To demonstrate the infectiousness of the virus from the qPCRpositive, small-mammal samples, experimental rabbit infections were performed under negative pressure in the BSL2 facilities of CITA. Eight 12-wk-old, laboratory-raised New Zealand white rabbits (Oryctolagus cuniculus) were inoculated intramuscularly with $0.3 \mathrm{~mL}$ of supernatant $(0.22 \mu \mathrm{m}$ poresize filtered) derived from $0.2 \mathrm{~g}$ of smallmammal livers homogenized in $1 \mathrm{~mL}$ of sterile phosphate-buffered saline. Two rabbits, reared in separate cages, were injected simultaneously with the inoculum obtained from each small-mammal liver, even if the liver was qPCR negative. Infections were carried out in separate experiments performed across several months.

The rabbits were monitored for $3 \mathrm{wk}$ postinoculation. Deceased animals were necropsied; surviving animals were also necropsied after being humanely euthanized. Samples from the liver, spleen, kidneys, thymus, and duodenum were collected to detect viral RNA by qPCR. A subset of the same tissue samples was fixed in $10 \%$ buffered formalin and processed using standard procedures for histological examination. The entire VP60 gene of the virus was sequenced
(Calvete et al. 2018), from the liver samples of 37 wild rabbits, as well as from the laboratory rabbits that died from RHD. Therefore, the full capsid VP60 sequence was used to infer phylogenetic relationships in this study. Phylogenetic trees were estimated using the maximum likelihood (ML) method available in MEGA7 (Kumar et al. 2016) under the best-fit nucleotide substitution model determined by the same software. The Tamura 3-parameter model (Tamura 1992) with a discrete gamma distribution was used to model evolutionary rate differences among sites (five categories; Gamma parameter $\mathrm{G}=0.1917$ ). Bootstrap resampling was performed on 1,000 replicates of the ML trees. The antibody status of the surviving inoculated rabbits was tested on days 0 and 21 after inoculation using a commercial indirect ELISA test (Ingezim Rabbit, INGENASA Lab, Madrid, Spain). The animal experiments were done in compliance with the provisions of Spanish national and European laws and approved by the CITA Ethical Committee for Animal Experimentation (protocol 2014-19).

Duplex qPCR was positive for GI.2/ RHDV2/b in one pine vole (Md-Nov14-P3) and in both white-toothed shrew samples (CrFeb15-P1 and Cr-Jun15-P4), with Cq values of $36.5,32.5$, and 38, respectively. All of the 37 wild rabbits were also qPCR-positive for the same virus at mean (SD) Cq values of 18.7 (2.04). This value is in agreement with Calvete et al. (2018), who reported Cq values ranging from 18.03 to 18.30 using the same qPCR procedures in rabbits that had died from acute RHD caused by the same virus. Although qPCR was not developed to quantify viral RNA copy numbers (Calvete et al. 2018), the high $\mathrm{Cq}$ values found in the small mammals suggested a lower quantity of viral particles than in rabbits killed by acute disease.

Death by acute RHD occurred in both laboratory rabbits infected with the inoculum obtained from Md-Nov14-P3 and in one rabbit infected with the inoculum from $\mathrm{Cr}$ Jun15-P4. Major histopathological lesions were found in the primary target tissues of the RHD virus, such as the liver, spleen, lung, and kidneys. Most of the severe lesions were 
TABLE 1. Results of qPCR to detect GI.2/RHDV2/b virus RNA in the liver of small mammals found dead in enclosures (P1-P4) housing European rabbits (Oryctolagus cuniculus). Two, laboratory-raised, New Zealand white rabbits were inoculated simultaneously with the inoculum obtained from each small mammal liver. Results of rabbit experimental infection, including rabbit liver qPCR and seroconversion in surviving rabbits, are summarized. Identification of small mammals (ID): Md-Sep14-P3 and Md-Nov14-P3, Mediterranean pine voles (Microtus duodecimcostatus) found dead in September and November 2014, respectively, both in enclosure P3; Cr-Feb15-P1 and Cr-Jun15-P4, white-toothed shrews (Crocidura russula) found dead in February and June 2015 in $\mathrm{P} 1$ and $\mathrm{P} 4$ enclosures, respectively.

\begin{tabular}{|c|c|c|c|c|c|}
\hline \multicolumn{2}{|c|}{ Small mammals } & \multicolumn{4}{|c|}{ Results of rabbit challenges } \\
\hline ID & Liver $\mathrm{Cq}$ & Rabbit no. & RHD death & Liver Cq & Seroconversion \\
\hline \multirow[t]{2}{*}{ Md-Sep14-P3 } & Negative & 1 & No & Negative & No \\
\hline & & 2 & No & Negative & No \\
\hline \multirow[t]{2}{*}{ Md-Nov14-P3 } & 36.5 & 3 & Yes & 16.4 & $\mathrm{NA}^{\mathrm{a}}$ \\
\hline & & 4 & Yes & 19.4 & NA \\
\hline \multirow[t]{2}{*}{ Cr-Feb15-P1 } & 32.5 & 5 & No & Negative & Yes \\
\hline & & 6 & No & Negative & No \\
\hline \multirow[t]{2}{*}{ Cr-Jun15-P4 } & 38.0 & 7 & Yes & 20.0 & NA \\
\hline & & 8 & No & 40.5 & Yes \\
\hline
\end{tabular}

${ }^{\mathrm{a}} \mathrm{NA}=$ Not applicable.

found in the liver, displaying acute necrotizing hepatitis. Changes in the spleen included diffuse red pulp hyaline necrosis, whereas in the lungs, multifocal acute alveolar edema and hemorrhages were seen resulting from massive disseminated intravascular coagulation. Multifocal acute tubular necrosis and fibrin thrombi were also observed in kidneys. The presence of GI.2/RHDV2/b in the liver tissue was confirmed by ${ }^{\mathrm{PCR}}$ with $\mathrm{Cq}$ values ranging from 16.4 to 20 .

No histopathological changes were observed in the rabbits that survived challenge. The results of the qPCR analysis were negative for all tissue samples except for the liver and the spleen of the surviving rabbit challenged with the Cr-Jun15-P4 inoculum. In this instance, GI.2/RHDV2/b RNA was found with high $\mathrm{Cq}$ values in the spleen and liver (40.5 and 42, respectively), which were, nevertheless, out of the lowest limit of detection $(\mathrm{Cq}=38.7)$ established for $\mathrm{qPCR}$ (Calvete et al. 2018). Seroconversion was detected in two surviving rabbits: one challenged with Cr-Feb15-P1 inoculum, and the survivor from the Cr-Jun15-P4 inoculum challenge. The results are summarized in Table 1.
Phylogenetic patterns of the viral samples from the 37 wild rabbits, whose sequences were deposited in GenBank under the accession numbers KY498543-52 and KY49855581 (Fig. 1 and Table 2), showed evidence of high viral diversification, with just eight pairs of identical sequences. Clustering was mainly related to year of isolation, and a complete homology of nucleotide sequences occurred only between samples obtained from rabbits that died in the same enclosure, in the same or in a contiguous month (seven pairs), with the exception of one pair of samples (Zar20155 and Zar2015-7) collected in different enclosures but in the same month.

The complete VP60 sequences obtained from the dead rabbits inoculated with the pine vole (GenBank accession number KY498553) or the white-toothed shrew inoculum (GenBank accession number KY498554) had 100\% nucleotide homology, even though the whitetoothed shrew was found in a different enclosure 7 mo after the pine vole. No complete homology with any wild rabbit sample was found, although the small-mammal isolate sequences were more similar to those collected during 2015-16. The pine vole isolate, collected in November 2014, clustered among the 2015 wild rabbit samples. It also 
TABLE 2. Sequences of the entire VP60 gene of rabbit hemorrhagic disease virus GI.2/RHDV2/b strain used for phylogenetic analysis. The Zar2013-1 to Zar2016-4 strains were detected in a Mediterranean pine vole (Microtus duodecimcostatus) and two white-toothed shrews (Crocidura russula) associated with European wild rabbits (Oryctolagus cuniculus) in Zaragoza Province, Spain. The names of the strains conform to those shown in Figure 1.

\begin{tabular}{ll}
\multicolumn{1}{c}{ Sequences } & \multicolumn{1}{c}{ GenBank accession numbers } \\
\hline Zar2013-1 to Zar2016-4 & KY498543-81 \\
Group France and Italy & FR819781, HE819400, HE800529-32, HE819400, HE800529-32, KC345611-13, \\
& JX106023, KT737803, KC907712 \\
Italy-Co12 & KT737802 \\
Italy-Sr12-2 & KC741409 \\
Group Malta & KJ957809-10 \\
Group Portugal I & KF442963-4, KF442961-2, KM115697-8, KM115680-2, KM115711, KM115689, \\
& KM115683 \\
Group Portugal II & KT000290-91, KT000306, KT000313, KT000329, KT000337, KT000339, KT000342, \\
& KM115714-16, KM115712-13 \\
Portugal-CBVal16 & KM979445 \\
Spain-CBAnd1 & KP090976 \\
Spain-N11 & KM878681 \\
Spain-Rij06-12 & KP129395 \\
Spain-Seg08-12 & KP129396 \\
Spain-Tar06-12 & KP129397 \\
Spain-Zar11-11 & KP129398 \\
Spain-Zar06-12 & KP129399 \\
\hline
\end{tabular}

exhibited a high similarity in nucleotide sequences and a complete homology at the amino acid level with a rabbit sample collected from the same enclosure (P3) in March 2016 (17 mo later).

Both pine voles and white-toothed shrews are species that are sympatric to the European wild rabbit. The findings of our survey may be the consequence of passive viral transmission to small mammals (with no effective virus replication), due to their scavenging habits, or by the ingestion of dead, infected rabbit tissue or feces. Supporting this idea, Shien and Lee (2000) detected viral RNA in the liver of piglets up to $14 \mathrm{~d}$ after a subcutaneous inoculation of GI.1, although there was no evidence of viral replication in the porcine tissues. Moreover, Zheng et al. (2003) demonstrated the presence of GI.1 viral RNA in the lymph nodes and livers of domestic cats experimentally fed RHD virus-infected rabbit livers. The RNA was detected 45-52 d after feeding, although viral replication was also not observed.
Genetic variability of RHD virus is high and mainly driven by time, with exact homologies occurring between isolates obtained in temporal proximity (Muller et al. 2009). Therefore, the complete homology that we found between the small-mammal isolate sequences was unique. Given the long-term survival of RHD viruses in animal tissues - at least $91 \mathrm{~d}$ (Henning et al. 2005) — the complete homology of the VP60 sequence could be a consequence of the fact that carcasses of RHD-infected rabbits may have been accessible to small mammals for several months following the last RHD outbreak, thus allowing for the ingestion of the same or related viruses. Under this hypothesis, the role of small mammals in RHD epidemiology may be negligible or restricted to viral dissemination by feces at a local scale.

The virus that was found in small mammals, however, was capable of infecting laboratory rabbits and causing RHD. If passive transmission to small mammals occurred, then the detected viral RNA would be expected to have originated from immunocomplexes of GI.2/ 


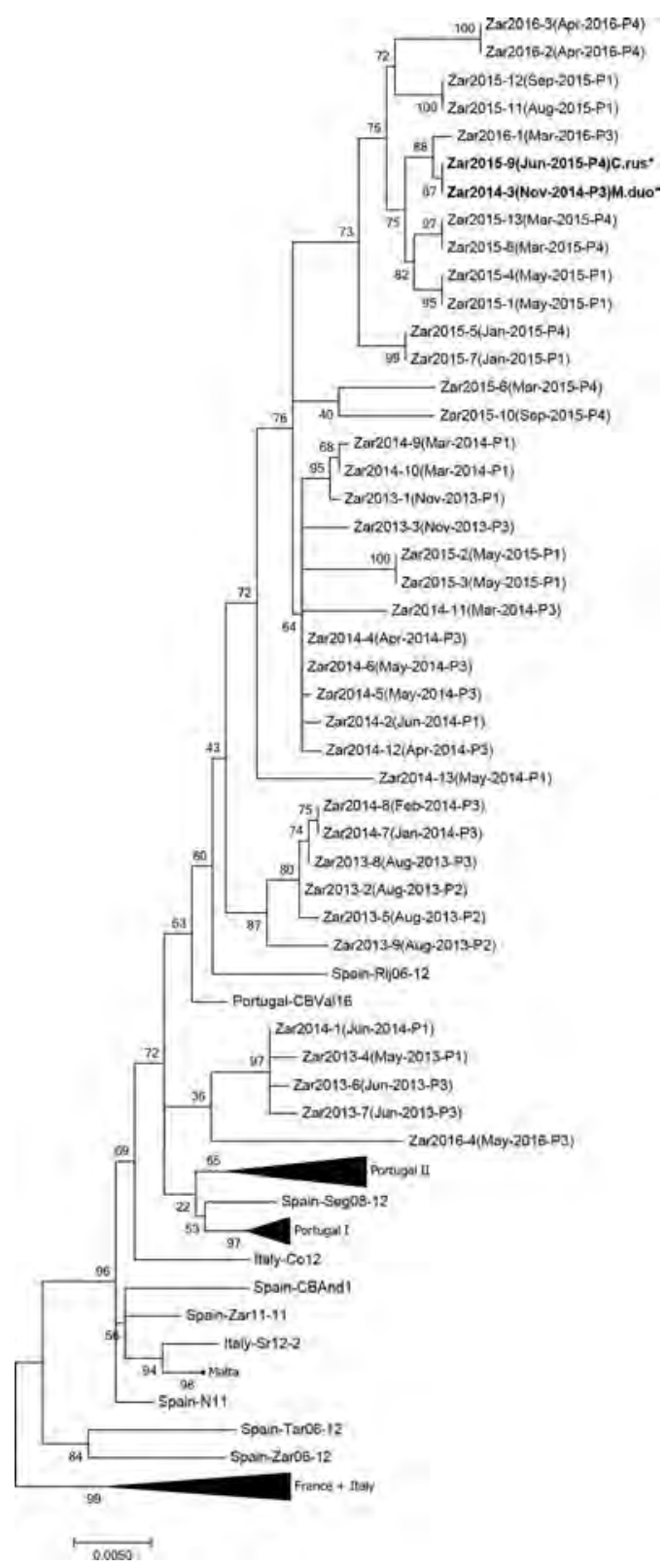

Figure 1. Maximum likelihood tree of the VP60 gene of of rabbit hemorrhagic disease virus, GI.2/ RHDV2/b. Bootstrap values of the nodes are shown next to them. Scale bar indicates the nucleotide substitutions per site. To facilitate visualization some groups were collapsed. Zar2013-1 to Zar2016-4 are sequences obtained from a Mediterranean pine vole (Microtus duodecimcostatus) and two white-toothed shrews (Crocidura russula) associated with European wild rabbits (Oryctolagus cuniculus) in Zaragoza Province, Spain. Collecting date and rabbit population for them are in parentheses. GenBank accession numbers of the sequences used in this study are in Table 2. Isolates from M. duodecimcostatus (M.duo) and C. russula (C.rus) in bold.
RHDV2/b particles and antibodies. That is, the existence of an infective virus would not be expected unless both small mammals died before they could mount an immune response against the viral antigens. Therefore, the finding of infective virus might point to the possibility of cross-species infection. This possibility has already been suggested by Merchán et al. (2011), who reported the detection of RHD viral RNA belonging to the GI.1 genotype in two wild mouse species in Spain, and by Rocha et al. (2017), who reported the experimental transmission of GI.1 virus from rabbits to these same mouse species. Given that these small-mammal species are sympatric to European leporids and that the origin of RHD etiological agents is not well understood (Abrantes et al. 2012), there is a need for further studies to better understand the role of small mammals in RHD epidemiology.

The study was funded by a Research and Development collaboration project between Agrifood Research and Technology Centre of Aragon (CITA) and the Animal Health Department of TRAGSATEC (INMUNIZADOS 1316) as well as by the E-RTA201400009-00-00 project from the National Institute for Agricultural and Food Research and Technology (INIA).

\section{LITERATURE CITED}

Abrantes J, van der Loo W, Le Pendu J, Esteves PJ. 2012. Rabbit haemorrhagic disease (RHD) and rabbit haemorrhagic disease virus (RHDV): A review. Vet Res 4:12.

Calvete C, Mendoza M, Alcaraz A, Sarto MP, Jiménez de Bagüés MP, Calvo AJ, Monroy F, Calvo JH. 2018. Rabbit haemorrhagic disease: Cross-protection and comparative pathogenicity of GI.2/RHDV2/b and GI.1b/RHDV lagoviruses in a challenge trial. Vet Microbiol 219:87-95.

Henning J, Meers J, Davies PR, Morris RS. 2005. Survival of rabbit haemorrhagic disease virus (RHDV) in the environment. Epidemiol Infec 133:719-730.

Kumar S, Stecher G, Tamura K. 2016. MEGA7: Molecular Evolutionary Genetics Analysis version 7.0 for bigger datasets. Mol Biol Evol 33:1870-1874.

Le Pendu J, Abrantes J, Bertagnoli S, Guitton JS, Le GallReculé G, Lopes AM, Marchandeau S, Alda F, Almeida T, Célio AP, et al. 2017. Proposal for a unified classification system and nomenclature of lagoviruses. J Gen Virol 98:1658-1666. 
Merchán T, Rocha G, Alda F, Silva E, Thompson G, de Trucios SH, Pagés A. 2011. Detection of rabbit haemorrhagic disease virus (RHDV) in nonspecific vertebrate hosts sympatric to the European wild rabbit (Oryctolagus cuniculus). Infect Genet Evol 11: 1469-1474.

Muller A, Freitas J, Silva E, Le Gall-Recule G, Zwingelstein F, Abrantes J, Esteves PJ, Alves PC, van der Loo, W, Kolodziejek J, et al. 2009. Evolution of rabbit haemorrhagic disease virus (RHDV) in the European rabbit (Oryctolagus cuniculus) from the Iberian Peninsula. Vet Microbiol 135:368-373.

Rocha G, Alda F, Pagés A, Merchán T. 2017. Experimental transmission of rabbit haemorrhagic disease virus (RHDV) from rabbit to wild mice (Mus spretus and Apodemus sylvaticus) under laboratory conditions. Infect Gen Evol 47:94-98.

Shien JH, Lee LH. 2000. Susceptibility of piglets to rabbit hemorrhagic disease virus following experimental infection. Can J Vet Res 64:134-137.

Tamura K. 1992. Estimation of the number of nucleotide substitutions when there are strong transition-transversion and G + C-content biases. Mol Biol Evol 9: 678-687.

Zheng T, Lu G, Napier AM, Lockyer SJ. 2003. No virus replication in domestic cats fed with RHDV-infected rabbit livers. Vet Microbiol 95:61-73.

Submitted for publication 11 May 2018.

Accepted 20 July 2018. 